\title{
Disfunção Hepática Aguda em Paciente com Hipertireoidismo e Hepatite por Vírus B: Recuperação após Plasmaférese e Tireoidectomia - Relato de Caso
}

apresentação de caso

\author{
Débora VieIRa SoAREs \\ LUIZ T. NAKAMURA \\ MÁrCIA C. B. LADEIRA \\ SELMA M. BRITO \\ JODÉLIA L. M. HeNRIQUES
}

Disciplina de Endocrinologia da

Faculdade de Ciências Médicas (FCM) da Universidade Estadual do Rio de Janeiro (Uerj), RJ, Brasil (DVS, JLMH); Disciplina de Clínica

Médica da FCM da Uerj, Rio de Janeiro, RJ, Brasil (LTN, MCBL);

Unidade de Hemoterapia do

Hospital Universitário Pedro

Ernesto (Hupe) da Uerj, Rio de Janeiro, RJ, Brasil (SMB).

Recebido em 22/05/2006

Aceito em 05/11/2007

\author{
RESUMO
}

Paciente masculino, 31 anos, internado com quadro de dor abdominal, náuseas, vômitos, icterícia e febre, iniciado há duas semanas. História de hipertireoidismo e tratamento irregular com propiltiuracil há dois anos, interrompeu a medicação quando iniciou o quadro atual. Apresentava bócio difuso, cerca de $120 \mathrm{~g}$, T4L 22,7 ng/dL (VN 0,8-1,9 ng/dL); TSH < 0,002 $\mu \mathrm{UI} / \mathrm{mL}$ (VN 0,4-5 $\mu \mathrm{UI} /$ $\mathrm{mL}$ ). Transaminases, bilirrubinas total e direta séricas elevadas. Foi mantido sem antitireoidiano e iniciado propranolol até a dose de $480 \mathrm{mg} / \mathrm{dia}$. Ultrasonografia de abdome foi normal e sorologias para hepatites A, B e C indicaram infecção aguda por vírus B. Ocorreu piora da função hepática e manutenção de níveis elevados de hormônios tireoidianos. Visando evitar necessidade futura de antitireoidiano, obter rápida normalização dos níveis de hormônios tireoidianos e em virtude do tamanho do bócio foi indicado tireoidectomia. $O$ paciente foi submetido a uma sessão de plasmaférese terapêutica, imediatamente antes da cirurgia, e tireoidectomia subtotal sem intercorrências. No quinto dia após a cirurgia, o paciente apresentava melhora da função hepática e baixos níveis séricos de T4 livre. Concluímos que o hipertireoidismo prévio pode exacerbar e perpetuar a disfunção hepática causada por hepatite viral aguda e que a plasmaférese é um meio rápido, seguro e eficaz de reduzir os níveis de hormônio tireoidiano, permitindo uma tireoidectomia bem-sucedida em pacientes com tireotoxicose grave. (Arq Bras Endocrinol Metab 2008; 52/3:566-571)

Descritores: Tireóide; Tireotoxicose; Plasmaférese; Fígado; Hepatite

\section{ABSTRACT}

Acute Hepatic Failure in a Patient with Hyperthyroidism and Virus B Hepatitis: Recovery after Plasmapheresis and Thyroidectomy - a Case Report.

A 31-year-old man admitted with abdominal pain, nauseas, vomiting, jaundice and fever that had began 2 weeks before. He had a history of hyperthyroidism and an irregular treatment with propylthiouracil (PTU) for 2 years. $\mathrm{He}$ had stopped PTU when the current symptoms started. The patient presented diffuse goiter, about 120g, FT4 $22.7 \mathrm{ng} / \mathrm{dL}$ (N: $0.8-1.9 \mathrm{ng} / \mathrm{dL}$ ); THS $<0.002 \mu \mathrm{UI} /$ $\mathrm{mL}(\mathrm{N} \mathrm{0.4-5} \mu \mathrm{Ul} / \mathrm{mL})$. Transaminases, serum total and direct bilirubins were increased. He was kept without PTU and propranolol was started and increased until the dose of $480 \mathrm{mg} /$ day. Abdominal ultrassonography was normal and serologic markers for hepatitis $A, B$ and $C$ pointed to acute virus $B$ hepatitis. The patient presented a worse of hepatic function and elevated thyroid hormones levels. To avoid the future need of antithyroid drugs, to get a fast normalization of thyroid hormones levels and because of the goiter size thyroidectomy was recommended. The patient underwent one therapeutic plasmapheresis session just before the surgery. A total thyroidectomy was performed without complications. At the $5^{\text {th }}$ day after surgery the patient pre- 
sented improvement of hepatic function and low FT4 serum levels. We concluded that preexisting hyperthyroidism may aggravate or perpetuate a hepatic failure caused for acute viral hepatitis and plasmapheresis is a rapid, reliable and effective way to lower thyroid hormones serum levels, allowing a successful thyroidectomy in patients with severe thyrotoxicosis. (Arq Bras Endocrinol Metab 2008; 52/3:566-571)

Key words: Thyroid; Thyrotoxicosis; Plasmapheresis; Liver; Hepatitis

\section{INTRODUÇÃO}

ISFUNÇÃO HEPÁTICA PODE Ocorrer em casos de tireotoxicose grave. Os achados laboratoriais mais comuns são hipoalbuminemia, elevação das transaminases e da fosfatase alcalina e alargamento discreto do tempo e atividade de protrombina (TAP). As anormalidades desaparecem com o tratamento do hipertireoidismo. As prováveis causas dessa disfunção são insuficiência cardíaca congestiva, desnutrição, infecções intercorrentes e um efeito tóxico direto dos hormônios tireoidianos. $\mathrm{O}$ consumo esplâncnico de oxigênio $\left(\mathrm{O}_{2}\right)$ aumenta enquanto o fluxo de sangue pouco se modifica. Dessa forma, a diferença de $\mathrm{O}_{2}$ arteriovenosa, por meio do leito esplâncnico, aumenta, e a hipóxia, nas áreas portais, pode ser fator contribuinte para a disfunção hepática (1).

Por outro lado, o tratamento com drogas antitireoidianas também é capaz de gerar dano hepático, que pode variar desde disfunção subclínica até hepatite aguda fulminante (2). A coexistência de uma infecção hepática aguda e de tireotoxicose em um mesmo paciente pode agravar o quadro clínico e gerar uma série de dilemas no seu manejo.

Relatamos o caso de um paciente com bócio difuso tóxico, disfunção hepática aguda e hepatite viral associada.

\section{RELATO DE CASO}

Paciente de 31 anos, masculino, foi internado na enfermaria da clínica médica com quadro de dor abdominal, náuseas, vômitos, febre, diarréia e prurido, iniciado há duas semanas e que fora, a princípio, tratado com antieméticos e analgésicos.

O paciente tinha diagnóstico de doença de Graves (DG) há cerca de dois anos. Fazia uso irregular de propiltiuracil (PTU) $1.200 \mathrm{mg} /$ dia. Apresentava baixa adesão ao tratamento e períodos de ausência do ambulatório de endocrinologia, refutando, inclusive, uma indicação prévia de tireoidectomia. Nas avaliações de ambulatório, a função hepática e o hemograma encontravam-se sempre dentro da normalidade. Os últimos exames foram realizados há três meses.

Há cerca de uma semana interrompeu, por conta própria, o PTU. Estava em uso de propranolol 160 $\mathrm{mg} /$ dia. Era funcionário de um supermercado e negava tabagismo ou etilismo.

Ao exame apresentava-se: ictérico, hipocorado, emagrecido. Pressão arterial: $170 \times 80 \mathrm{mmHg}$, freqüência cardíaca: $104 \mathrm{bpm}$, freqüência respiratória: $18 \mathrm{inc} / \mathrm{min}$, peso: $58 \mathrm{~kg}$, índice de massa corporal: $19 \mathrm{~kg} / \mathrm{m}^{2}$. Bócio difuso, móvel, cerca de $120 \mathrm{~g}$, sem frêmito ou sopro. Ritmo cardíaco regular, em dois tempos, sopro pancardíaco. Abdome doloroso à palpação, sem dor à descompressão. Tremores de extremidades e pele quente. Sem sinais ou sintomas oculares de oftalmopatia de Graves.

Exames na internação: ultra-sonografia de abdome dentro da normalidade. T4L 22,7 ng/dL (VN 0,8-1,9 $\mathrm{ng} / \mathrm{dL}$ ); TSH < 0,002 $\mu \mathrm{UI} / \mathrm{mL}$ (VN 0,4-5 $\mu \mathrm{UI} / \mathrm{mL}$ ); Albumina 2,2 g/dl (VN 3,1-4,3 g/dl); TAP 92\% (VN 65-100\%); AST $255 \mathrm{U} / \mathrm{L}(\mathrm{VN} 10-34 \mathrm{U} / \mathrm{L})$; ALT 547 $\mathrm{U} / \mathrm{L}(\mathrm{VN}$ 9-45 U/L); fosfatase alcalina $478 \mathrm{U} / \mathrm{L}(\mathrm{VN}$ 44-155 U/L); bilirrubina total (BT) $37 \mathrm{mg} / \mathrm{dL}$ (VN até $1,1 \mathrm{mg} / \mathrm{dL}$ ); bilirrubina direta (BD) $28 \mathrm{mg} / \mathrm{dL}$ ( $\mathrm{VN}$ até $0,25 \mathrm{mg} / \mathrm{dL}$ ). Coombs direto e indireto negativos. Marcadores sorológicos para hepatites A e C (anti-HAV, anti-HCV) negativos. Avaliação para hepatite B: $\mathrm{HBeAg}$ e anti-HBs negativos; $\mathrm{HBsAg}$, anti-HBc total, anti-HBc IgM e Anti-HBe positivos. Anti-HIV negativo. Demais exames na Tabela 1 .

Foi mantido sem antitireoidiano, por causa do risco de piora da lesão hepática, e aumentado propranolol até a dose de $480 \mathrm{mg} /$ dia.

Evoluiu com agravamento da diarréia, emagrecimento de $16 \mathrm{~kg} \mathrm{em} 20$ dias, necessitando inclusive de nutrição enteral. Em razão da anemia foi submetido à hemotransfusão. Ocorreu piora da função hepática (TAP: 66\%; AST: 379 U/L e ALT: 1.007 U/L) e manutenção de níveis elevados de hormônios tireoidianos [T4L: $26,7 \mathrm{ng} / \mathrm{dL}$ e 
Tabela 1. Sumário de exames laboratoriais.

\begin{tabular}{|c|c|c|c|c|c|c|}
\hline Exames & Internação & & Evolução & & Pré-op & V N \\
\hline Bilirrubina total (mg/dL) & 37 & 37,6 & 39,3 & 15,8 & 14,8 & até 1,1 \\
\hline Bilirrubina direta $(\mathrm{mg} / \mathrm{dL})$ & 28 & 24,3 & 27,4 & 15,7 & & até 0,25 \\
\hline Fosfatase Alc (U/L) & 478 & 171 & 134 & & & 44 a 155 \\
\hline Gama GT (U/L) & 33 & & 25 & & & 4 a 50 \\
\hline Albumina (g/dL) & 2,2 & & 2,5 & & & 0,8 a 1,9 \\
\hline Glicose (mg/dL) & 89 & 63 & 77 & 75 & & 70 a 100 \\
\hline Uréia (mg/dL) & 33 & 45 & 40 & 78 & & 10 a 45 \\
\hline Creatinina $(\mathrm{mg} / \mathrm{dL})$ & 0,5 & & 0,1 & & 0,9 & 0,4 a 1,4 \\
\hline Sódio (mEq/L) & 137 & & 138 & 136 & & 136 a 146 \\
\hline Potássio (mEq/L) & 3,8 & & 3,8 & 3,8 & & 3 a 5 \\
\hline Hemácia (milhões/mm³) & 4,25 & 3,63 & 3,5 & 2,63 & 3.54 & 4,4 a 5,9 \\
\hline Hemoglobina (g/dL) & 11,6 & 10 & 9.8 & 7,56 & 10,5 & 13 a 18 \\
\hline Hematócrito (\%) & 33,5 & 28,9 & 28,6 & 21,1 & 29.6 & 40 a 54 \\
\hline Leucócitos (mil/mm³) & 4,92 & 6,01 & 8,3 & 8,43 & 6,7 & 4,0 a 11,0 \\
\hline Basófilos (\%) & 0 & 0,6 & 0,2 & 0 & 0 & 0 a 1 \\
\hline Eosinófilos (\%) & 1 & 2,3 & 0,8 & 1 & 0 & 1 a 5 \\
\hline Mielócitos (\%) & 0 & 0 & 0 & 0 & 0 & 0 \\
\hline Metamielócitos (\%) & 0 & 0 & 0 & 0 & 0 & 0 \\
\hline Bastão (\%) & 1 & 1 & 5 & 1 & 2 & 1 a 7 \\
\hline Segmentados (\%) & 34 & 41 & 59 & 59 & 80 & 40 a 55 \\
\hline Linfócitos (\%) & 42 & 38 & 27 & 28 & 10 & 22 a 45 \\
\hline Monócitos (\%) & 19 & 17 & 12 & 11 & 8 & 2 a 10 \\
\hline Plaquetas (mil/mm³) & 196 & 175 & 240 & 171 & 213 & 150 a 450 \\
\hline TAP (\%) & 92 & 72 & 78 & 66 & 68 & 65 a 100 \\
\hline
\end{tabular}

$\mathrm{VN}=$ valores normais; TAP $=$ tempo e atividade de protrombina

T3L: $2.000 \mathrm{pg} / \mathrm{dL}$ (VN 140-440 pg/dL)] (Figuras l e 2 e Tabela 1 ).

Foi indicada tireoidectomia, a fim de evitar necessidade futura de antitireoidiano, obter rápida normalização dos níveis de hormônios tireoidianos e por causa do tamanho do bócio.

$\mathrm{Na}$ tentativa de melhorar as condições préoperatórias, foi administrada solução de Lugol por 10 dias. Contudo o valor do T4L permaneceu elevado, $35,3 \mathrm{ng} / \mathrm{dL}$. O paciente foi, então, submetido à plasmaférese terapêutica imediatamente antes da cirurgia, com remoção de uma volemia plasmática e reposição com albumina humana a $4 \%$; o T4L pré-operatório era $4,9 \mathrm{ng} / \mathrm{dL}$. A tireoidectomia subtotal foi realizada sem intercorrências com boa evolução pós-operatória. No primeiro dia pósoperatório, T4L 4,0 ng/dL. Após o quinto dia de cirurgia: AST: $86 \mathrm{U} / \mathrm{L}$, ALT: $183 \mathrm{U} / \mathrm{L}$, fosfatase alcina: $113 \mathrm{U} / \mathrm{L}, \mathrm{BT}: 7,4 \mathrm{mg} / \mathrm{dL}$ e T4L: $0,9 \mathrm{ng} / \mathrm{dL}$. O paciente recebeu alta para acompanhamento ambulatorial em uso de levotiroxina $50 \mu \mathrm{g} /$ dia.

\section{DISCUSSÃO}

Relatamos o caso de um paciente com bócio difuso tóxico e grave disfunção hepática aguda associada. O paciente foi submetido a plasmaférese e tireoidectomia, levando ao rápido controle da função tireoidiana e à melhora da disfunção hepática.

Nas avaliações ambulatoriais prévias, a internação feita antes e após o início do antitireoidiano a função hepática era normal e não foi feita avaliação para infecção por vírus da hepatite B (HVB). Acreditava-se tratar-se de paciente 


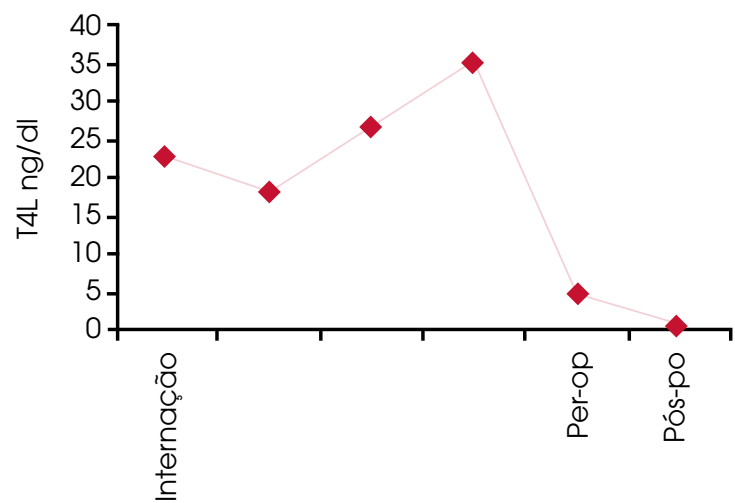

$\mathrm{T} 4 \mathrm{~L}=$ tiroxina livre, valores normais: 0,8 a $1,9 \mathrm{ng} / \mathrm{dL}$

Figura 1. Evolução dos níveis de T4L.

em fase aguda final de infecção pelo HVB, por apresentar marcadores que são positivos nesta fase (3), como HBsAg (permanece positivo por até 24 semanas após o início da infecção), anti-HBc IgM (é marcador de infecção recente, encontrado no soro até 32 semanas e não está presente na infecção crônica) e anti-HBe (sugere redução da replicação viral e pode estar presente em fase aguda final). Anti-HBs negativo fala contra cura e imunidade, HBeAg negativo indica queda na replicação viral. Sabe-se ainda que perfis sorológicos atípicos podem ocorrer no curso da infecção pelo HVB $(3,4)$. Avaliações realizadas um ano após o quadro de hepatite aguda evidenciaram cura da hepatite com evolução para anti-HBs reagente e $\mathrm{HBsAg}$ não-reagente.

O hormônio tireoidiano (HT) tem influência na função hepática. Os hepatócitos são células altamente responsivas ao HT e têm a maioria dos seus receptores para TSH localizados intranucleares (5). O HT modula a atividade de várias organelas dentro dos hepatócitos, destacando-se a sua ação nas mitocôndrias, onde age aumentando o consumo de oxigênio e a fosforilação oxidativa $(6,7)$. Na maioria dos pacientes com hipertireoidismo, a ocorrência de disfunção hepática se dá em virtude dos efeitos metabólicos do excesso de HT e da hipóxia tecidual, que ocorre como resultado do aumento de consumo de oxigênio esplâncnico e do aumento da demanda de oxigênio hepático (8).

A lesão hepática associada ao hipertireoidismo pode variar de leve alteração nos testes de função hepática e alterações histopatológicas não específicas até necrose hepática. Alguns estudos demonstraram correlação entre a função tireoidiana e as alterações histológicas (9). Foi relatada uma freqüência de hepatomegalia de até 33\% (10) e de icterícia variando entre $5,3 \%$ e $50 \%(10,11)$.

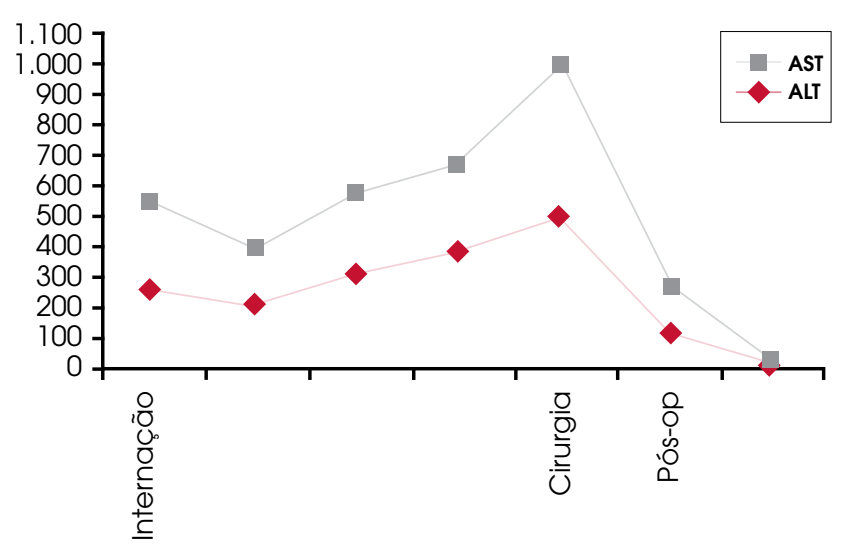

AST = aspartato aminotrasferase, valores normais: 10 a $34 \mathrm{U} / \mathrm{L} ; \mathrm{ALT}$ = alanina aminotrasnferase, valores normais: 9 a $45 \mathrm{U} / \mathrm{L}$.

Figura 2. Evolução dos níveis de transaminases.

A prevalência de alterações em testes de função hepática em pacientes com hipertireoidismo é em média de $75 \%(11,12)$, mas pode variar de $15 \%$ a $90 \%$ (13). Em contraste, a presença de hepatite clínica aguda é menor que 1\%. Enquanto alguns estudos demonstram elevação mais freqüente da gama GT (13), outros indicam a fosfatase alcalina (principalmente à custa da fração óssea) como teste mais comumente alterado (11). Em um estudo que avaliou 95 pacientes com hipertireoidismo sem alterações cardíacas e com testes negativos para hepatite viral, a freqüência de elevação nos níveis de AST e ALT foi de 28,4\% e 38,3\%, respectivamente (11). Fong e cols. (10) demonstraram elevação de ALT em 67\% dos hipertireóideos estudados. As enzimas hepáticas se normalizam na maioria dos pacientes com a restauração do estado eutireoidiano, o que sugere fortemente que a elevação nos níveis de AST e ALT ocorre por causa do hipertireoidismo $(11,12)$.

A utilização de drogas antitireoidianas também é causa de disfunção hepática em pacientes com hipertireoidismo $(2,11)$. Elevações transitórias e assintomáticas de ALT e Gama GT foram descritas por Huang e cols. (11) em um terço dos pacientes tratados com PTU. Possivelmente, isso ocorre em virtude de leve lesão hepática induzida pelo PTU, não havendo necessidade de suspensão da terapia. Por outro lado, a incidência de PTU induzindo hepatite clínica variou de $0,1 \%$ a $1,2 \%(2,11)$, sendo nestes casos a terapia com antitireoidiano contra-indicada. Alguns pacientes podem apresentar necrose hepática submaciça e o desfecho fatal ocorreu em $20 \%$ destes casos. Contudo, a maioria dos pacientes se recuperou com a simples retirada do PTU (14). Apesar da descrição de hepatite 
aguda grave por PTU ser considerada rara na literatura (14), revisão dos dados do banco de transplante americano entre 1990 e 2002 mostrou que, excluindo-se os pacientes um uso de acetoaminofem, o PTU era a segunda droga relacionada a transplante hepático por lesão medicamentosa, representando $9,5 \%$ dos casos (15). O mecanismo pelo qual o PTU causa lesão hepática ainda não está bem esclarecido, podendo tratar-se de toxicidade direta ou reação idiossincrásica.

No caso descrito, acredita-se que o hipertireoidismo crônico não compensado e o tratamento com PTU poderiam gerar um estresse metabólico e tóxico ao fígado. Esta associação predisporia ao curso fulminante da hepatite viral concomitante. A melhora da disfunção hepática, após a tireoidectomia, sugere que o principal fator causador desta disfunção era a tireotoxicose. Contudo, a infeç̧ão pelo HVB e o uso de PTU poderiam contribuir para a severidade da evolução, tendo em vista que o quadro era bastante grave; o paciente estava em caquexia, alimentando-se via enteral, com diarréia, acolia, anemia e valores de ALT 13 vezes acima da normalidade.

As terapias para a DG visam a inibição da síntese de hormônios tireoidianos, destruição ou remoção do tecido da tireóide e são os agentes antitireoidianos, radioiodo ou cirurgia. A embolização arterial de tecido tireoidiano mostrou-se também eficaz (16), mas sua aplicação é pouco difundida e não conta com muitos estudos. Ainda não é possível tratar os fatores patogênicos básicos na DG, e a falta de concordância sobre qual seria a melhor terapia decorre do fato de que nenhuma delas seja a ideal (17).

As drogas antitireoidianas ainda são a primeira opção de tratamento para pacientes jovens, com hipertireoidismo moderado, bócio pequeno, oftalmopatia ativa, crianças, adolescentes e mulheres grávidas ou lactentes (18). Para pacientes com contra-indicação aos antitireoidianos ou que apresentem menores chances de remissão (bócio volumoso, hipertireoidismo grave com níveis muito elevados de T3 e T4 e relação $\mathrm{T} 3 / \mathrm{T} 4>20)$, muitos têm indicado o tratamento com radioiodo como primeira opção $(18,19)$. Atualmente, a cirurgia tem suas indicações bastante limitadas, como crianças e gestantes com efeitos colaterais, não aderência ou não resposta da tireotoxiose às drogas antitireoidianas, bócios volumosos com sintomas compressivos e suspeita de doença maligna associada. Outra vantagem da cirurgia é o restabelecimento imediato do eutireoidismo.

Este caso ilustra o dilema de se tratar um paciente com doença hepática aguda e hipertireoidismo. As dro- gas antitireoidianas, como descrito anteriormente, apresentam um risco de hepatotoxicidade e devem ser usadas com cautela em pacientes com doença hepática ativa ou descompensada, por isso optou-se pela suspensão do PTU. O radioido demora, no mínimo, 30 dias, e, em média, 90 dias para o controle da tireotoxicose e fatores como bócio volumoso e T4 livre elevado, este é o caso do nosso paciente, são prognósticos de falência ao radioiodo (19) e podem implicar a necessidade de uma segunda dose, sendo, algumas vezes, necessário manter o paciente em uso de antitireoidiano até que se atinja o eu ou o hipotireoidismo.

No caso descrito, o controle da tireotoxicose poderia levar à rápida normalização das enzimas e da função hepática, como se observou posteriormente. Este controle é mais rapidamente obtido com tireoidectomia, evitando-se, inclusive, a necessidade posterior do uso de drogas antitireoidianas, o que poderia ter ocorrido se optasse pelo radioiodo, representando um risco adicional de hepatotoxicidade. Indicou-se então tratamento cirúrgico para o nosso paciente.

Todavia, o risco cirúrgico de um paciente com níveis tão elevados de HT é bastante alto. O preparo cirúrgico envolvendo o uso de drogas antitireoidianas ficou dificultado pelo risco de piora da disfunção hepática. $\mathrm{O}$ uso de preparações com iodo e corticosteróide também tem sido sugerido por alguns autores (20) no preparo pré-operatório de pacientes com DG. No caso relatado, a utilização do lugol foi pouco eficaz em reduzir os níveis de HT. Em nosso paciente, o tratamento com plasmaférese reduziu significativamente os níveis de HT (Figura 1), resultando um preparo pré-operatório rápido e eficaz.

No tratamento de pacientes com tireotoxicose, a plasmaférese é utilizada há vários anos (21), de maneira segura e eficiente. Tem sido empregada em casos, tanto de crise tireotóxica quanto de agranulocitose, vasculite, hepatotoxicidade e outros efeitos adversos induzidos por PTU ou metimazol (21-24). Podem ser realizadas uma ou mais sessões. Os HT (mais de 99\%) estão quase inteiramente ligados a proteínas plasmáticas e podem ser efetivamente removidos com plasmaférese. A concentração da fração livre também diminui. Um possível mecanismo para a ocorrência desse fato pode ser a redistribuição e a diluição dos HT da parte intracelular para o fluido reposto. Além disso, a reposição com albumina humana ou plasma fresco provê novos sítios de ligação para a fração livre de HT (22).

As proteínas da coagulação e as plaquetas também podem ser removidas com a plasmaférese, podendo 
ocorrer coagulopatia clínica ou subclínica no período imediatamente pós-plasmaférese. Contudo, estas alterações raramente estão associadas a hemorragias significativas e só ocorrem em pacientes submetidos a vários procedimentos de plasmaférese terapêutica $(25,26)$.

No caso apresentado, o hipertireoidismo estava levando ao agravamento do quadro de hepatite viral e hepatotoxicidade. O controle da tireotoxicose, após a tireoidectomia, levou à rápida resolução da disfunção hepática (Figura 2), com redução significativa das transaminases e início da reposição de levotiroxina no quinto dia de pós-operatório.

Conclui-se que o hipertireoidismo prévio pode exacerbar e perpetuar a disfunção hepática causada por hepatite viral aguda e que a plasmaférese é um meio rápido e seguro de reduzir os níveis de hormônio tireoidiano, permitindo uma tireoidectomia bem-sucedida em pacientes com tireotoxicose grave.

\section{AGRADECIMENTOS}

Agradecemos ao professor Mário Vaisman por rever este relato de caso.

\section{REFERÊNCIAS}

1. Davies TF, Larsen PR. Thyrotoxicosis. In: Larsen PR, Kronenberg HM, Melmed S, Polonsky KS, editores. Williams textbook of endocrinology. $10^{\text {th }}$ ed. Philadelphia: Elsevier Science; 2003. p. 374-421.

2. Kim H-J, Kim B-H, Han Y-S, Yang I, Kim K-J, Dong S-H, et al. The incidence and clinical characteristics of symptomatic propylthiouracil-induced hepatic injury in patients with hyperthyroidsm: a single-center retrospective study. Am J Gastroenterol. 2001;96:165-9.

3. Ministério da Saúde, Secretaria de Vigilância em Saúde. Hepatites virais: o Brasil está atento. $2^{\mathrm{a}}$ ed. 2005. p. 17.

4. Ganem D, Prince AM. Hepatitis B virus infection - natural history and clinical consequences. N Engl J Med. 204; 350:1118-29.

5. Oppenheimer JH, Schwartz HL, Surks MI. Tissue differences in the concentration if triiodothyronine nuclear binding sites in the rat: liver kidney, pituitary, heart, brain, spleen, tests. Endocrinology. 1974;95:897-903.

6. Horst C, Rokos H, Seitz HJ. Rapid stimulation of hepatic oxygen consumption by 3,5-di-iodo-L-thyronine. Biochem J. 1989;261:945-50.

7. Liverini G, lossa S, Barletta A. Relationship between resting metabolism and hepatic metabolism: effect of hypothyroidism and 24 hours fasting. Horm Res. 1992;38:154-9.

8. Bayraktar M, van Thiel DH. Abnormalities in measures of liver function and injury in thyroid disorders. Hepatogastroentrology. 1997;44:1614-18.
9. Sola J, Pardo-Mindan FJ, Zozaya J, Quiroga J, Sangro B, Prieto J. Liver changes in patients with hyperthyroidism. Liver. 1991;11:193-7.

10. Fong TL, McHulchinson JG, Reynolds TB. Hyperthyroidism and hepatic function. A case series analysis. J Clin Gastroenterol. 1992;14:240-4.

11. Huang M-J, Li K-L, Wei JS, Wu S-S, Fan KD, Liaw YF. Sequential liver and bone changes in hyperthyroidism: prospective controlled follow-up study. Am J Gastroenterol. 1994;89:1071-6.

12. Thompson $P$, Strum $D$. Abnormalities of liver function tests in thyrotoxicosis. Milit Med. 1978;143:548-51.

13. Gauana A, Gajst O, de Felice MC, Guillen C, Sartorio G, Viale F, et al. Modifications of serum hepatic enzymes in thyrotoxic patients with and without treatment. Medicina. 1988;48:17-21.

14. Ichiki Y, Mitsuteru A, Yamashita N, Morita C, Maruyama T, Horiuchi T, et al. Propylthiouracil-induced severe hepatitis: A case report and review of the literature. J Gastroenterol. 1998;33:747-50.

15. Russo MW, Galanko JA, Shrestha R, Fried MW, Watkins P. Liver transplantation of acute liver failure from drug induced liver injury in the United States. Liver Transplantation. 2004; 10:1018-23.

16. Xiao H, Zhuang W, Wang S, Yu B, Chen G, Zhou M, et al. Arterial embolization: a novel approach to thyroid ablative therapy for Graves' disease. J Clin Endocrinol Metab. 2002;87:3583-9.

17. Singer PA, Cooper DS, Levy ER, Ladenson PW, Braverman LE, Daniels G, et al. Treatment guidelines for patients with hyperthyroidism and hypothyroidism. Standars of Care Committee, American Thyrroid Association. JAMA. 1995;273:808-12.

18. Cooper DS. Antithyroid drugs. N Engl J Med. 2005;352:905-17.

19. Andrade VA, Gorss JL, Maia AL. lodo radioativo no manejo do hipertireoidismo da doença de Graves. Arq Bras Endocrinol Metab. 2004;48:159-65.

20. Panzer C, Beazley R, Braverman L. Rapid preoperative preparation for severe hyperthyroid Grave's disease. J Clin Endocrinol Metab. 2004;89:2142-4.

21. Ashkar FS, Katims RB, Smoak WM, Gilson AJ. Thyroid storm treatment with blood exchange and plasmapheresis. JAMA. 1970;16:1275-79.

22. Ozbey N, Kalayoglu-Besisik S, Gul N, Bozbora A, Sencer E, Molvalilar S. Therapeutic plasmapheresis in patients with severe hyperthyroidism in whom antithyroid drugs are contraindicated. Int Clin Prat. 2004;58:554-8.

23. Enghofer M, Badenhoop K, Zeuzem S, Schmidt-Matthiesen A, Betz C, Encke A, at al. Fulminant hepatitis A in a Patient with severe hyperthyroidism: rapid recovery from hepatic coma after plasmapheresis and total thyroidectomy. J Ciln Endocrinol Metab. 2000;85:1765-9.

24. Schlienger JL, Faradji A, Sapin R, Blickle JF, Chabrier G, Simon C, et al. Traitement de l'hyperthyroïdie grave par échange plasmatique. Press Med. 1995;14:1271-4.

25. Yeh JH, Chin HC. Coagulation abnormalities in serial doublefiltration plamapheresis. J Clin Apheresis. 2001;16:139-42.

26. Wood L, Jacops P. The effect of serial therapeutic plasmapheresis on platelet count, coagulation factors, plasma immunoglobulin and complement levels. J Clin Apheresis. 1986;3:124-8.

Endereço para correspondência:

Débora Vieira Soares

Av. Maracanã, 1523/203 - Tijuca

2051 1-000, Rio de Janeiro RJ

E-mail: wellbs@terra.com.br 